Divers@ Revista Eletrônica Interdisciplinar,

Matinhos, v. 13, n. 1, p. 78-91, jan./jun. 2020

ISSN 1983-8921

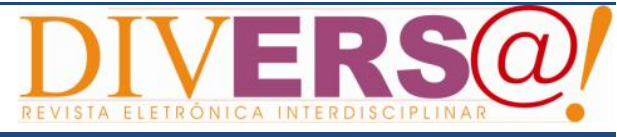

\title{
ECOFORMAÇÃO TRANSDISCIPLINAR: REFLEXÕES ACERCA DA CRISE PSICOSSOCIOECOLÓGICA GLOBAL NA ERA PLANETÁRIA*
}

\section{TRANSDISCIPLINARY ECOFORMATION: REFLECTIONS ON THE GLOBAL PSYCHOSOCIOECOLOGICAL CRISIS IN THE PLANETARY AGE}

Juceli Aparecida Silva ${ }^{1}$

\begin{abstract}
Resumo
Este artigo tem como objetivo abordar o enfoque de ecoformação transdisciplinar a partir de reflexões acerca da crise psicossocioecológica global, que vem sendo discutida nos meios acadêmicos e governamentais desde o final da década de 1960. A metodologia selecionada baseou-se na revisão ordenada de textos acadêmicos sobre o tema. Argumenta-se que a noção de ecoformação transdisciplinar constitui um desdobramento do novo paradigma sistêmico na ciência contemporânea, designando um dispositivo de aprendizagem transformadora ecologizada que poderia, em princípio, favorecer uma metamorfose cultural ao mobilizar pesquisa, ação e formação de modo dialógico e contínuo. Concluiu-se que este enfoque ecopedagógico é um componente essencial no enfrentamento dessa crise global.
\end{abstract}

Palavras-chave: Tecnociência; Ecopedagogia; Ensino educativo; Metamorfose cultural; Paradigma sistêmico-complexo; Edgar Morin.

\begin{abstract}
This paper aims to address the transdisciplinary ecoformation approach from reflections on the global psychosocioecological crisis, which has been discussed in academic and governmental media since the late 1960s. The selected methodology was based on the orderly revision of academic texts. About the subject. It is argued that the notion of transdisciplinary ecoformation is an offshoot of the new systemic paradigm in contemporary science, designating a transformative green learning device that could, in principle, favor a cultural metamorphosis by mobilizing research, action and formation in a dialogic and continuous way. It was concluded that this ecopedagogical approach is an essential component in facing this global crisis.
\end{abstract}

Keywords: Technoscience; Ecopedagogy; Educational teaching; Cultural metamorphosis; Systemiccomplex paradigm; Edgar Morin.

Artigo Original: Recebido em 01/11/2019 - Aprovado em 30/06/2020

${ }^{1}$ Psicóloga com Formação em Terapia Comportamental e Cognitiva. Doutoranda e Mestra pelo Programa de Pós-Graduação em Sociologia Política - PPGSP na Universidade Federal de Santa Catarina (UFSC). e-mail: juceli_s@hotmail.com (autor correspondente)

* Apoio financeiro: O presente trabalho foi realizado com apoio da Coordenação de Aperfeiçoamento de pessoal de Nível Superior - Brasil (CAPES) - Código do Financiamento 001. 
1 Introdução

[...] nossa salvação coletiva é evitar o desastre de uma morte prematura da humanidade [...]. (MORIN; KERN, 1995: p. 182).

Com o início das grandes navegações no século $\mathrm{XV}$, ingressamos na "Era planetária". Ela tem sido marcada pela violência em todas as suas formas (direta e estrutural), culminando numa dinâmica errática que, especialmente nas últimas cinco décadas, passou a colocar em risco as condições básicas de reprodução da vida na biosfera. Podemos encontrar evidências exemplares dessa dinâmica na persistência de modelos de desenvolvimento socioeconômico com perfil economicista, que respondem por impactos cada vez mais destrutivos nos ecossistemas e paisagens (MORIN; KERN, 1995).

Apesar da expansão vertiginosa do conhecimento que forjamos do mundo, de forma geral as universidades continuam, paradoxalmente, atreladas ao paradigma científico analítico-reducionista e, por implicação, defasadas em relação à necessidade de promover estratégias à altura desses desafios (STERLING, 2010; CAPRA, 1990). A síndrome de fragmentação do conhecimento cultivada pela "tecnociência sem consciência" nos impede de entender a "aventura cósmica" do qual fazemos parte e, assim, de compreender nossa "identidade terrestre" em sua unidade/diversidade complexa e multidimensional. A tecnociência nos prometeu o progresso, mas alimentou a agonia planetária em níveis sem precedentes ${ }^{\mathrm{i}}$.

No âmbito dessa crise que afeta os fundamentos da civilização industrial-tecnológica, os recursos comuns da humanidade são percebidos como "bens gratuitos" - e praticamente inesgotáveis - sujeitos aos mecanismos usuais de compra e venda nos mercados globalizados. O crescimento intensivo e ilimitado (no tempo) das economias nacionais se impõe como uma crença que desafia, desde o início dos anos 1970, os diagnósticos centrados na prospecção dos "limites biosféricos" da utilização [antropocêntrica] de ecossistemas e paisagens (VIEIRA, 2016; MERÇON, 2019; RIST, 2012).

Mesmo após décadas de estudos e propostas, ainda permanecemos reféns de um sério "déficit de alfabetização ecológica". Mesmo aqueles que supostamente já se emanciparam das desilusões geradas pela cultura do "progresso a qualquer custo" costumam muitas vezes se render às "astúcias do Sistema". Conceitos como "desenvolvimento sustentável" e "decrescimento" são pensados, debatidos, abandonados e revistos pelos diferentes teóricos que atuam no campo da ecologia política

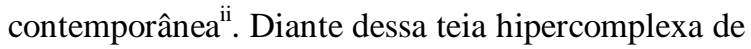
desafios, admitindo as nossas limitações para compreendê-los e enfrentá-los, podemos pelo menos manter - com Edgar Morin - a "esperança na desesperança”, procurando possibilidades éticas de atuação (VIEIRA, 2016; BESSON-GIRARD, 2012; RIST, 2012).

Diamond (2005) nos faz observar que podemos aprender com os erros do passado, evitando repetílos. Tomar decisões precipitadas, mesmo que bem intencionadas, não seria uma solução lúcida. Nossas culturas são barreiras frágeis contra a barbárie da qual somos capazes, e essa constatação é tanto preocupante quanto preciosa para nós - agora em busca de uma ecoformação transdisciplinar (PINEAU; GALVANI, 2012; BESSON-GIRARD, 2012).

Neste sentido, Peter Russel (1992) observa que em nossa vontade de aprimorar a qualidade de vida, acabamos por cair nos perigos da tecnociência. Somos, segundo o autor, seduzidos pela ilusão de que controlar o mundo seja a resposta para todas as nossas necessidades. $\mathrm{O}$ apego que temos às coisas materiais nas nossas relações pessoais, interpessoais e com o mundo é afetada explicitamente pelo nosso consumo e pelo nosso "amor" ao dinheiro.

O medo das incertezas que nos faz querer controlar o mundo para que as coisas saiam do jeito que queremos parece ser justamente o que tem nos levado aos dramas e impasses do nosso tempo. Isso nos força a gastar muita energia e tempo pensando no futuro, mais do que vivendo o próprio presente. Assim, vivemos o que poderíamos considerar uma "crise de consciência" segundo Russel (1992) ou uma "crise da percepção" (CAPRA, 1990), na qual nossa compreensão emocional, comportamental e de pensamentos sobre a multidimensionalidade planetária ainda está adormecida devido a nossa compreensão fragmentada da realidade.

A política totalitária, tecnicista, burocrática e voltada aos interesses econômicos das elites precisa ser repensada, de modo a integrar a 
multidimensionalidade e a totalidade dos problemas humanos. Enquanto Homo Sapiens Demens ${ }^{\text {iii }}$, podemos levar adiante o projeto de "hominização". Mas o princípio da "ecologia da ação" deveria ser ponderado como uma condição sine qua non de lucidez numa "estratégia antropolítica" ou de “metadesenvolvimento" (MORIN; KERN, 1995).

A noção de ecoformação transdisciplinar designa, neste contexto, uma metamorfose cultural em todos os seus níveis, buscando superar os bloqueios constitutivos da crise psicossocioecológica global ${ }^{\text {iv }}$. Ela se propõe a unir o tripé: pesquisa, ação e formação constantes através da auto-eco-formação (PINEAU; GALVANI, 2012). Neste sentido, o objetivo deste artigo é de oferecer um tratamento exploratório desta noção-chave de ecoformação transdisciplinar, sintonizada com a busca de compreensão da globalidade e complexidade da condição humana na Era planetária. Para tal, utilizei-me da Revisão ordenada da literatura de textos acadêmicos sobre o tema como forma de coleta de dados.

Para que o objetivo desta pesquisa se cumpra, pretendo primeiramente situar as bases epistemológicas que condicionaram a sua gênese e evolução ao longo das últimas três décadas. Em sequência, abordo a discussão acerca do conceito de ecoformação transdisciplinar e alguns resultados de sua prática. Pelo fato de se tratar de uma temática complexa, limito-me a apresentar um panorama dos seus aspectos teóricos e empíricos mais essenciais.

\section{Bases epistemológicas da pesquisa socioecológica}

[...] as partes estão no todo, que está nas partes. (VIEIRA, 2016: p. 29).

O processo de maturação gradual do conceito de ecoformação transdisciplinar decorre do avanço das pesquisas no campo das ciências socioecológicas. Por sua vez, este campo é tributário da emergência do novo paradigma científico sistêmico-complexo. No que se segue, de forma ainda exploratória, serão apontados alguns dos principais pontos de referência que devem ser levados em conta na compreensão da sua potencialidade como uma abordagem transgressiva do debate contemporâneo sobre alternativas educacionais face à crise psicossocioecológica global. A escolha desses parâmetros se deu a partir das convergências identificadas numa revisão inicial da bibliografia pertinente - como indica o Quadro 1.

Quadro 1 - Principais acontecimentos do século XX na área do ecodesenvolvimento

\begin{tabular}{|c|c|}
\hline Ano & Acontecimento \\
\hline 1962 & $\begin{array}{c}\text { Publicação do Livro Primavera } \\
\text { Silenciosa }\end{array}$ \\
\hline 1968 & Criação do Clube de Roma \\
\hline 1972 & $\begin{array}{c}\text { Relatório Meadows } \\
\text { Conferência de Estocolmo }\end{array}$ \\
\hline 1986 & Carta Mundial da natureza \\
\hline 1992 & Rio-92 \\
\hline
\end{tabular}

Fonte: desenvolvido pela autora.

Em 1962, Rachel Carson lançou uma obra intitulada "Primavera silenciosa", que mudaria o curso da história (CARSON, 1969). Este livro aborda os impactos socioecológicos destrutivos gerados pelo uso de pesticidas. A mensagem da autora contribuiu não só para a criação de leis e normas voltadas à regulamentação do uso de agrotóxicos. Estimulou também uma reflexão pioneira acerca das contradições da civilização industrial-tecnológica e da necessidade de instituirmos um novo código de conduta nas nossas relações com a biosfera.

Poucos anos após o lançamento deste livro, um pequeno e seleto grupo de profissionais, empresários, diplomatas, cientistas, educadores, humanistas, economistas e altos funcionários governamentais de dez diferentes países se reuniram para tratar do debate internacional sobre os "limites do crescimento material num planeta de recursos naturais finitos". Este debate foi deflagrado pela publicação do famoso Relatório Meadows, em 1972, elaborado segundo uma metodologia sistêmicav ${ }^{\mathrm{v}}$ no Massachusetts Institute of Technology (MIT) por uma equipe coordenada por Donella e Denis Meadows (1973). Os cenários tendenciais contidos nesse relatório, mobilizando um leque de variáveis socioeconômicas, demográficas, socioculturais, sociopolíticas e socioecológicas (interdependentes), alimentaram a formação de uma nova área de pesquisa socioecológica: a ecologia política. 
Impulsionaram também a realização da primeira reunião de cúpula da história - em Estocolmo - sob os auspícios das Nações Unidas. Duas e três décadas após, a mesma equipe colocou em discussão na comunidade científica suas reavaliações da pertinência dos resultados alcançados no relatório inicial (MEADOWS; MEADOWS; RANDERS, 1993; MEADOWS, 2014) ${ }^{\mathrm{vi}}$.

$\mathrm{Na}$ Conferência de Estocolmo foram apresentadas sete proclamações e vinte e seis princípios comuns, com o intuito de oferecer aos povos do mundo inspiração e guia para preservar e melhorar o meio ambiente humano (ONU, 1972). Em 1986, a ONU adotou a "Carta Mundial da Natureza" como forma de chamar novamente a atenção da humanidade sobre a persistência dos condicionantes estruturais da crise global, não obstante os sinais de alerta anunciados por ocasião da Cúpula de Estocolmo (WEDY, 2018).

$\mathrm{Na}$ década de 1990 emergiu uma nova Conferência de Cúpula promovida pelas Nações Unidas no Rio de Janeiro, agora focalizando o binômio Meio Ambiente \& Desenvolvimento. Esta foi, até aquele momento, a maior reunião de chefes de Estado já promovida, contando com a participação de 20 mil pessoas oriundas de 179 países. A proposta de uma Agenda 21 global foi endossada por todos os representantes governamentais participantes do evento. Nela comparece pela primeira vez o conceito de desenvolvimento sustentável (VIEIRA, 2016).

Apesar dessas iniciativas, o que se percebe cinquenta anos após a publicação da obra de Carson em 1962 é que a "tecnociência sem consciência" continua a prevalecer nas tomadas de decisão política em todos os níveis de governo. Dos inúmeros desafios que foram evidenciados ao longo dessa trajetória, Vieira (2016) e Vieira, Berkes e Seixas (2005) destacam três: os epistemológicos, os éticos e os políticos.

Os desafios epistemológicos que precisam ser superados dizem respeito, por um lado, à complexidade envolvida na busca de entendimento das inter-relações entre as dinâmicas naturais e sociais. O novo paradigma sistêmico-complexo continua ocupando um espaço marginal nas comunidades científicas, submetidas aos efeitos da compartimentação e da desarticulação dos saberes
(MORIN, 2010). Por outro lado, torna-se indispensável promover a integração inter e transdisciplinar do conhecimento: todas as ciências que conhecemos - naturais e socioculturais, básicas e aplicadas, são chamadas a contribuir para a maturação de uma nova ecologia humana norteada pelo pensamento sistêmico-complexo (MORIN, 2010; BESSON-GIRARD, 2012).

Os desafios éticos dizem respeito à superação da ética (antropocêntrica) do domínio sobre a natureza pela ética (ecocêntrica) da comunidade de seres, tendo em vista a fundamentação de um novo estilo de desenvolvimento e de uma nova abordagem ecopedagógica (VIEIRA, 2016). Neste sentido,

Tudo isso deve contribuir para a formação de uma consciência humanística e ética de pertencer à espécie humana, que só pode ser completa com a consciência do caráter matricial da Terra para a vida, e da vida para a humanidade. Tudo isso deve contribuir, igualmente, para o abandono do sonho alucinado de conquista do Universo e dominação da natureza. (MORIN, 2010: p. 39).

Finalmente, cabe uma referência aos desafios políticos envolvidos na instituição de processos participativos de tomada de decisão no campo do planejamento e da gestão das relações que mantemos com a natureza (MORIN, 2003; 2010; VIEIRA, 2016; PINEAU; GALVANI, 2012). Pois nos regimes de democracia representativa que conhecemos ainda predomina uma cultura política marcada pelo enfraquecimento do senso de responsabilidade e da "solidariedade orgânica" entre as pessoas e entre as pessoas e os ecossistemas e paisagens (MORIN, 2010).

\section{Gênese e evolução do enfoque de ecodesenvolvimento}

A gênese do pensamento ecodesenvolvimentista está intimamente ligada aos trabalhos pioneiros sobre o binômio ambiente \& desenvolvimento empreendidos no âmbito do Centre International de Recherche sur l'Environnement et le Developpement (CIRED) na década de 1970. Partiu-se do entendimento de que a biosfera é um microssistema complexo, composto por ecossistemas, cuja plasticidade é cada vez mais ameaçada pela ação antrópica. As pesquisas iniciais visavam superar a 
dicotomia preservacionismo-conservacionismo na condução de um debate atualizado sobre os limites ecológicos do crescimento material (VIEIRA, 2016).

A ecologia clássica, entendida como o 'estudo do habitat' passou por transformações profundas desde a sua concepção por Ernst Haeckel na segunda metade do século XIX. Partiu do entendimento da "diversidade de aspectos interdependentes envolvidos" para, no século XX, vir a tornar-se uma "ciência de síntese", incorporando o campo das ciências humanas e sociais (VIEIRA, 2016).

Neste sentido, a formação da subárea intitulada biopolítica consolidou-se desde a década de 1960 como expressão de um movimento de hibridização de fatores biológico-evolucionistas e socioculturais em busca de um processo unitário e convergente

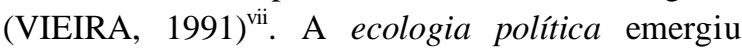
como uma derivação desta subárea, estando diretamente ligada à elucidação dos condicionantes estruturais da crise socioecológica em escala planetária. A ênfase incidia na compreensão das limitações congênitas da representação economicista do fenômeno do desenvolvimento. A linha de argumentação estipulava que o subsistema econômico na maior parte dos sistemas sociais modernos não considera adequadamente as dimensões centrais do conceito de meio ambiente enquanto: (1) fornecedor de recursos naturais; (2) espaço onde se dão as interações entre processos naturais e socioculturais; e (3) habitat, englobando a infraestrutura física e institucional que condiciona o contexto geral de vida (VIEIRA, 1991). A ecologia política passou a concentrar a produção de evidências relacionadas aos "limites do crescimento material", indicando assim a urgência de políticas transescalares de promoção da integração inter e transdisciplinar do conhecimento (VIEIRA, 1991).

Para os pesquisadores do CIRED a nova ética (multidimensional) do desenvolvimento deveria conjugar, de forma interdependente, os critérios de satisfação de necessidades básicas (materiais e intangíveis), equidade, "self-reliance", prudência ecológica e ecologização da economia. A ideia de uma nova economia de sistemas socioecológicos complexos - ou ecossocioeconomia - deveria transcender os limites das análises obtidas através de indicadores reducionistas de crescimento material, abarcando "novas dimensões" e "novos instrumentos de avaliação". Isso incluía a valorização das análises desenvolvidas nos campos da antropologia cultural e da história norteada pelo pensamento sistêmico (VIEIRA, 2016).

Por sua vez, a educação passou a ser considerada como o alicerce da construção de processos igualitários, participativos, frugais, pluralistas e promotores de descentralização e do empoderamento. Falava-se de uma educação para o desenvolvimento, alimentando o funcionamento de sistemas descentralizados de planejamento e gestão (VIEIRA, 2016). Por ocasião da Rio-92 o termo “desenvolvimento sustentável" passou a ser adotado na esperança de que, a partir dos diálogos advindos dessa perspectiva, pudéssemos superar o ideário neoliberal. Apesar desse esforço, o efeito foi justamente o oposto, no qual o conceito se tornou uma alavanca impulsionadora, criando uma fachada verde que mascarou a incompatibilidade entre desenvolvimento e sustentabilidade (RIST, 2012; VIEIRA, 2016).

Ao longo do tempo, o ideário inicial dos pesquisadores do CIRED foi revisto e ampliado, em busca de fundamentos teórico-metodológicos cada vez mais consistentes. Os modelos de análise passaram a incorporar os resultados da evolução da epistemologia sistêmica mediante a formação de um "pensamento complexo" (MORIN, 2003). A noção de "resiliência ecossistêmica" passou a ser tratada como um fator fundamental no planejamento e na gestão de estratégias alternativas de desenvolvimento. Além disso, emergiu a preocupação pelo entendimento da problemática dos modos de apropriação e gestão de recursos naturais de uso comum.

Defendia-se a necessidade de um estatuto jurídico legitimado e compartilhado para uma gestão democrático-participativa de conflitos socioecológicos identificados nos sistemas de planejamento e gestão relacionados ao "patrimônio natural e cultural da humanidade”. A noção de "economia da dádiva" veio adensar esses avanços conceituais, na linha do aprofundamento do assim chamado Movimento Anti-utilitarista nas Ciências Sociais: MAUSS ${ }^{\text {viii }}$ (VIEIRA, 2016).

Por fim, cabe uma referência à noção de ecoformação transdisciplinar, cunhada inicialmente por Gaston Pineau (2001) à frente de um grupo de pesquisas educacionais sediado na Universidade de 
Tours, na França - o Groupe de Recherches en Ecoformation / GREF - (COTTEREAU, 2001; GALVANI; PINEAU, 2012; MONEYRON, 2003).

Esta noção condensa a evolução do conceito inicial de educação para o ecodesenvolvimento e que foi assumida como o centro de gravidade da argumentação desenvolvida neste artigo em sua busca por compreensão da globalidade e complexidade da condição humana na Era planetária.

\section{Ecoformação transdisciplinar}

'O saber não nos torna melhores nem mais felizes.' Mas a educação pode ajudar a nos tornarmos melhores, se não mais felizes, e nos ensinar a assumir a parte prosaica e viver a parte poética de nossas vidas (MORIN, 2010: p. 11).

O enfoque de ecoformação transdisciplinar pode ser visto como o limiar atual de maturação do enfoque de educação para o ecodesenvolvimento (EPE), que se disseminou nos cinco continentes após a Conferência de Estocolmo - sobretudo em espaços informais de conscientização ecológica. Contribuiu sobretudo para viabilizar experimentos pioneiros de gestão de projetos de desenvolvimento local, sobretudo nos "países do Sul",ix. No final dos anos 1980, recebeu um vigoroso impulso da pesquisa didático-pedagógica conduzida em nome do enfoque de educação relativa ao meio ambiente (ERE) uma construção elaborada por um grupo interdisciplinar sediado na Universidade do Québec em Montréal (UQAM), no Canadá. A ênfase recaía no aperfeiçoamento de instrumentos de ensinoaprendizagem em espaços de educação formal (VIEIRA, 2016).

Após a realização da Rio-92, o debate sobre o tema tornou-se ainda mais denso com a disseminação do conceito de educação para o desenvolvimento sustentável. Os princípios básicos da EPE e da ERE compareciam nas formulações da metodologia de construção de Agendas 21 locais, mas os desvios ideológicos criados pela apropriação neoliberal do conceito de sustentabilidade passaram a exigir um esforço suplementar de revisão e atualização que favoreceu o surgimento do enfoque de ecoformação transdisciplinar (VIEIRA, 2016).
À luz da reflexão tardia sobre a dimensão da complexidade sistêmica, e por influência da filosofia da física quântica e da biologia da cognição, os vetores complementares do "aprender a aprender", do "aprender a conviver" e do "aprender a ser" passaram a ser integrados num movimento original de criação de novas estratégias de ensinoaprendizagem contínua, em espaços formal e informal, e ao longo de toda a vida. A elaboração de uma lógica do "terceiro incluído" estimulou a abertura de novas linhas de pensamento de cunho transdisciplinar, ou seja, constituindo uma "radicalização da visão sistêmica do mundo" (VIEIRA, 2016; MORIN, 2000; NICOLESCU, 2005).

As três linhas partiram da mesma base epistemológica sistêmica, compartilhando o intuito de direcionar os processos de ensino-aprendizagem visando o enfrentamento da crise socioecológica global. Mas a ET, a partir das contribuições de Gaston Pineau à frente do GREF, constitui uma "hibridização" original, que assegura uma conexão da auto-eco-formação guiada pela "lógica do terceiro incluído" e pela caracterização - de corte construtivista radical - de "níveis de realidade" (PINEAU; GALVANI, 2012; VIEIRA, 2016). Alcançamos assim uma "compreensão renovada do papel determinante exercido pelas forças vitais (indissociavelmente físicas e psíquicas), que nos conectam indissociavelmente com a natureza." (VIEIRA, 2016: p. 46). Dessa forma, este enfoque sistêmico-complexo-transdisciplinar alimenta, indo além das duas primeiras, as experimentações com práticas didático-pedagógicas em todos os níveis de ensino (PINEAU; GALVANI, 2012).

Para Gaston Pineau e Pascal Galvani (2012), mesmo no século XXI há o predomínio de um divórcio entre a formação docente e as experiências de vida que impedem que consigamos construir conhecimentos que contemplem a integralidade da nossa condição humana e assegurem a formação gradual de uma identidade terrestre avançando na contramão da cultura industrialista. Segundo eles, o estudo da condição humana depende de todas as formas de conhecimento. Somos animais marginais no universo e em nosso planeta (aqui, temos características muito particulares em relação aos outros animais não humanos). As disciplinas integrativas nos permitem conectar a condição 
humana nos níveis natural e metanatural (MORIN, 2010).

Neste sentido, nossa identidade terrestre somente poderá ser definida se nos situarmos, procurando entender com o máximo de lucidez possível onde estamos, de onde viemos e para onde iremos. Pois como sinaliza Edgar Morin (2000), foi a partir dos conhecimentos adquiridos no século $\mathrm{XX}$ que se tornou possível reconhecer o nosso "duplo enraizamento" - no cosmo físico e na esfera da vida -, com base na premissa de que o nosso universo foi constituído e está evoluindo na enigmática "aventura cósmica", a partir do Big Bang.

Ainda segundo Morin (2010), nós domamos a natureza vegetal e animal, pensando em sermos os senhores da Terra, mas estamos apenas começando a tomar consciência da "Terra-sistema", em toda a sua totalidade complexa físico-biológica-antropológica. Isso significa compreender que é muito recente - a partir das primeiras explosões atômicas - a formação do nosso senso de "comunidade de destino" na "Terra-Pátria", nutrida pelo reconhecimento da nossa identidade como espécie forjada ao longo de bilhões de anos de evolução na biosfera.

Segundo os teóricos da ecoformação transdisciplinar, consolidar o vetor do aprender a viver nos exigirá a formação de uma teoria tripolar complexa de formação que religue os polos individual, social e material. Uma teoria que legitime as experiências pessoais como parte dos aprendizados que ocorrem enquanto práticas de auto e coaprendizagem. A formação passa a ser compreendida enquanto um processo vital e permanente, ao longo da vida, composto pela interação de novas subjetividades com os outros e com o mundo (PINEAU; GALVANI, 2012).

Por sua vez, a partir do conceito de "aprendizagem transformadora ecologizada", Stephen Sterling (2010) defende que se faz necessário mudar não somente os pensamentos dos estudantes, mas refletir, avaliar e mudar os paradigmas vigentes que alimentam a manutenção desses pensamentos e das ações que compõem a hegemonia dominante. Isso somente é alcançado com o que considera como sendo uma mudança radical de nível de aprendizagem. Neste sentido, numa espiral ascendente, distingue (i) o nível de aprendizagem que corresponde a uma forma acrítica de adaptação ao mundo (senso comum), (ii) o nível de uma tomada de consciência mais reflexiva que leva em conta um ganho de aprendizagem sobre os condicionantes da aprendizagem, mas permanecendo restrito à epistemologia dualista hegemônica na modernidade industrialista; e finalmente (iii) o nível transformador-ecologizado, o qual exige percebermos reflexiva e criticamente as nossas visões de mundo em nome de uma leitura sistêmicatransdisciplinar.

Num outro diapasão, Edgar Morin (2010) argumenta que a organização dos conhecimentos evita a acumulação estéril de resultados fragmentados gerados pela pesquisa especializada. Esta capacidade deverá exigir uma metamorfose das instituições educacionais que está imbricada, recursivamente numa metamorfose do pensamento linear e dualista. Segundo ele, precisamos conectar os dois polos, pois "não se pode reformar a instituição sem uma prévia reforma das mentes, mas não se podem reformar as mentes sem uma prévia reforma das instituições" (MORIN, 2010: p. 99, grifos do autor). Com base nesse novo paradigma educacional sistêmico-complexo, trata-se de transformar as informações em conhecimento, e este em sapiência ('saberes + ciência') (MORIN, 2010).

Em termos práticos, Morin $(2010 ; 2000)$ nos propõe o "ensino educativo" $\mathrm{x}$ " e destaca que devemos nos capacitar para colocar em ação os "sete saberes para a educação do futuro". Estes sete saberes necessários à educação abordam problemas que comparecem em todos os níveis de ensinoaprendizagem. Tratam dos "sete buracos negros da educação", que são ignorados, subestimados ou fragmentados nos programas educativos na atualidade. São eles: o conhecimento, o conhecimento pertinente, a identidade humana, a compreensão humana, a incerteza, a condição planetária e a antropo-ética (MORIN, 2000).

Os sete saberes representam um desafio fundamental para os educadores atrelados aos paradigmas reducionistas ainda predominantes na civilização industrial-tecnológica. As metodologias a serem mobilizadas encontram-se atualmente em estágio embrionário, pelo fato de exigirem uma combinação criativa das dimensões reflexiva, dialógica e transdisciplinar desses processos historicamente inéditos (GALVANI; PINEAU, 2012). 
Tendo em vista assegurar a viabilidade operacional da teoria de Morin (2000), Pineau e Galvani (2012) nos oferecem um oitavo saber: o "saber alegre". Eles pressupõem que este tipo de saber foi desprezado e desconhecido ao longo da história ocidental. Juntamente aos outros sete saberes propostos por Morin, o saber alegre nos permitiria vivenciar todos os aspectos que envolvem o agir "transdisciplinar" xi. De modo talvez não tão otimista e reconfortante, Sterling ${ }^{\text {xii }}$ (2010) nos adverte que as mudanças de percepção causadas por "mudanças de terceira ordem", aquelas que nos fazem refletir sobre a forma como vemos o mundo, são difíceis e envolvem, geralmente, a resistência e até mesmo traumas, pois pressupõem mudanças radicais de crenças e ideias e expressam a [re]construção de novos significados - o que, na minha opinião, não deixa de ser uma perspectiva animadora, se bem que nem sempre divertida.

Nestas propostas globalizantes, os saberes experienciais e formais não podem estar dicotomizados. O ensino precisa englobar pesquisa, ação e formação numa estratégia contínua, no tempo longo. O saber transdisciplinar dentro desses oito saberes procura superar - biocognitivamente - as "cegueiras do conhecimento" que vivenciamos atualmente. Para tanto, deve basear-se nos princípios de um "conhecimento pertinente", que favoreça a "compreensão". Para tanto, seus objetos de saber englobariam as questões que já abordamos ao longo desse artigo: a condição humana, a identidade terrena, as incertezas e os desafios. Neste, professores são vistos como "aprendentes", haja vista que somente se pode ensinar bem no processo de aprendizado com os outros (PINEAU; GALVANI, 2012). Para Morin (2010) a missão de transmitir, a partir do pensamento sistêmicocomplexo, envolve arte, fé e amor.

Formar-se em complexidade é aprender a reconhecer as interdependências, as retroações e as recursividades que compõem a trama de nossas vidas. Interdependências generalizadas que nos constituem, a partir das quais emergem nossos atos, nossos diálogos, nossos símbolos. Formar-se em complexidade é ultrapassar o saber que reduz a realidade à materialidade concreta de objetos isolados, em identidades excludentes. Formar-se em complexidade é aprender a reconhecer para além do concreto material, este outro concreto de interação generalizada dos fenômenos. Formar-se em complexidade é operar a reflexão dessa realidade dialógica concreto em nossas vidas vividas (GALVANI; PINEAU 2012: p. 216217, grifos dos autores).

O pensamento complexo proposto por Morin na esfera educacional não aponta no sentido de um caminho fechado. Trata-se, antes, de um método que auxilia no entendimento de que o concreto é, em si mesmo, complexo. A complexidade mostra-se nas interdependências dialógicas que constituem a vida desde o seu começo, para além das dicotomias usuais do pensamento redutor. Em outras palavras, “[...] a complexidade é uma palavra problema e não uma palavra solução" (GALVANI; PINEAU, 2012: p. 216). Abrange os diferentes níveis de realidade, bem como os saberes teóricos, práticos e também poéticos da vida, que conectam de modo dialógico as pessoas e o mundo.

Em síntese, nos processos de ecoformação transdisciplinar precisamos nos ater aos sete saberes propostos por Morin (2000), além do oitavo sugerido por Pineau e Galvani (2012), exercitando a coaprendizagem e as histórias de vida. No que diz respeito à auto-ecoformação, ambos os autores propõem quatro estratégias reflexivas e dialógicas: *formar-se (autoformação), *refletir sobre as experiências vividas, *formar-se no contato dialógico com outros saberes, e *religar-se (em termos teóricos, práticos e poéticos).

Além dessas estratégias reflexivas gerais, os autores nos propõem outras mais específicas para o enfrentamento de cada um dos desafios envolvidos no exercício da ecoformação transdisciplinar. Para eles, quatro tríades nos ajudarão nesse processo:

- Pensar - Sentir - Atuar: religando a explicação, a compreensão e a ação, acompanhando as cegueiras do conhecimento.

- Formação - Pesquisa - Ação: religando estes três para açambarcar saberes criticamente e de modo transdisciplinar.

- Cultura - Natureza - Indivíduo: religando as pessoas a si mesmas, aos outros e ao mundo, reconhecendo sua condição humana.

- Razão formal - razão sensível - razão prática: religando os níveis de realidade e de sentido teórico, prático e poético (GALVANI; PINEAU, 2012). 
Aprender a afrontar as incertezas é um dos nossos desafios e Morin, ao longo de seu trabalho, nos mostra que não há um caminho fechado $\mathrm{e}$ pronto, que o cosmos, o mundo e nós mesmos estamos em constantes mudanças e as nossas ações precisam ser pensadas e avaliadas conforme a complexidade presente. Mostra-se enquanto um caminho de "iniciação à lucidez", no qual o erro é onipresente (GALVANI; PINEAU, 2012).

Thiollent e Colette (2014) reforçam que a pesquisa-ação na área de educação e formação de professores precisa englobar uma vasta gama de condições que incluem desde o resgate das tradições pedagógicas conhecidas, de pedagogos conceituados, de diversas técnicas de diferentes áreas, além de meios informacionais, audiovisuais e multimeios (mas limitando o uso de recursos de tecnologia da informação em favorecimento das interações sociais e participativas).

Ainda pouco explorada no campo da educação, a pesquisa-ação se mostra como uma metodologia importante na capacitação tanto de professores como de pesquisadores nas mais diversas situações, inclusive na interação com estudantes. "Nessa perspectiva, a diversidade cultural dos participantes, de seus comportamentos e formas de expressão, tem de ser respeitada e fortalecida." (THIOLLENT; COLETTE, 2014: p. 215). Respeita, dessa forma, valores humanistas e não os valores de mercado e poder.

Mesmo iniciativas locais, com baixo impacto governamental, econômico e geográfico, podem se destacar como fortes exemplos de pesquisa-ação para processos que almejem a expansão da solidariedade e da sustentabilidade. Elas precisam ser fortalecidas e visibilizadas de modo a açambarcar as particularidades conectoras existentes em suas experiências comunitárias sustentáveis e assim, consigam superar essas limitações macro institucionais (MERÇON; AYALA-OROZCO; ROSELL, 2018).

A ecoformação deve apoiar e incentivar experiências alternativas e comunidades que estão situadas além das esferas tradicionais da educação, oferecendo-lhes todo o suporte do pensamento complexo, aprimorando-se nesse diálogo transdisciplinar (PINEAU; GALVANI, 2012; GALVANI; PINEAU, 2012). De modo geral, a educação deve estimular a curiosidade, favorecendo a inteligência geral, o exercício da dúvida e o pensar bem (MORIN, 2010).

\section{Resultados da prática ecoformativa transdisciplinar}

Como pudemos constatar até aqui, muitas teorias, artigos, livros e conferências foram realizados a respeito da crise psicossocioecológica global desde que Carson (1969) publicou seu livro. Não sei quanto a quem me lê, mas sinto uma certa frustração no que diz respeito ao uso prático de todas essas formulações, haja vista que parecemos sempre ser atropelados por essa lógica industrial-tecnológica que nos trouxe até aqui. Apesar desse sentimento, podemos reunir vários exemplos de trabalhos que se esforçaram em unir conhecimentos acadêmicos, saberes locais e a ética planetária no intuito de gerar novas formas de aprendizado e quebra de paradigmas.

Referências quase clássicas, como Jean Piaget (1978), Leo Vigotskii, Romanovich e Leontiev (2010) e Paulo Freire (1987), nos fornecem evidências seminais. $\mathrm{Em}$ cenários mais contemporâneos, ao redor do mundo, temos vários exemplos dessas ações. Como não é o objetivo desse artigo trata-las em detalhes, sinto-me ao menos compelida a situar algumas dessas atividades destacadas pelos autores que utilizo.

Sterling (2010) menciona as ações educativas empreendidas por Hicks (2002), Rogers (1994) e O'Sullivan (2002), enfatizando que estes autores são unânimes em considerar que a "aprendizagem transformativa", concebida de uma perspectiva globalizante, precisa ir além da cognição, tocando mais profundamente os aprendizes envolvidos. Isto permitiria o empoderamento do aprendiz na arte de conviver com a própria dor e se envolver na busca de atenuação das dores do mundo. O ponto chave se encontra em compreender que este é um processo desafiador e no qual os profissionais envolvidos na tarefa sejam competentes para tal. Tanto os designers das ementas quanto os educadores precisam ter passado por esse processo, incentivando os estudantes a explorar a mudança epistêmica necessária de modo colaborativo.

Além dos autores já citados acima, Sterling (2010) sinaliza algumas instituições que apontam neste sentido, a exemplo do Schumacher College, da 
Universidade St. Andrews e da Universidade de Plymouth, todas no Reino Unido. Recomenda ainda uma tomada de contato com o Centro de Desenvolvimento Sistêmico da Universidade de Hawkesbury, na Austrália.

Já a educadora Juliana Merçon, no México, atua na colaboração transdisciplinar e de aprendizagem social com e para experiências do Sul global. Esteve envolvida num projeto de abrangência nacional baseado simultaneamente nas assim chamadas epistemologias do "Sul global", na decolonialidade do saber e do ser e na transdisciplinaridade. Esta corrente híbrida está centrada numa "ecopedagogia transdisciplinar", levando em consideração tanto o conhecimento (saber), a prática (fazer) e a política (o poder). O projeto envolveu membros de vários grupos que, de alguma forma, compartilhavam o interesse pela temática da "sustentabilidade" (MERÇON, 2019; MERÇON; AYALA-OROZCO; ROSELL, 2018; FRENK et al., 2016; REDSOCIOECOS, 2019). Dentre as várias conclusões alcançadas com esse trabalho, a pesquisadora destaca que a solidariedade e a confiança são pontos chaves para que a "educação transdisciplinar", conceito utilizado pela autora, seja alcançado. Elas precisam ser construídas e cultivadas nas relações para além da academia.

O filósofo e sociólogo Paulo Freire Vieira (2016) está envolvido em estratégias semelhantes de pesquisa-ação-formação há várias décadas, sempre inserido em redes transescalares. Desde 1987 vem coordenando o Núcleo Transdisciplinar de Meio Ambiente e Desenvolvimento (NMD) na Universidade Federal de Santa Catarina. Dentre as suas principais ações educativas no domínio da gestão integrada e compartilhada de zonas costeiras, podemos destacar a criação de um Fórum de Agenda 21 local da Lagoa de Ibiraquera (situada na porção centro sul do litoral catarinense); além do seu envolvimento na criação e na consolidação progressiva do Conselho Gestor da APA da Baleia Franca e também do Observatório do Litoral (uma linha de cooperação técnico-científica com o Ministério Público visando ao mesmo tempo o rastreamento de casos de violação ostensiva da legislação ambiental e o fomento do controle social de projetos, programas e políticas de desenvolvimento em curso na zona costeira catarinense (NMD, 2019). Mais recentemente, ele tem se concentrado na recepção, na pesquisa e na difusão do enfoque de ecoformação transdisciplinar - que se tornou a área de concentração dominante no âmbito do NMD-UFSC.

\section{Considerações finais}

Neste artigo procurei tecer algumas reflexões exploratórias a respeito do enfoque de ecoformação transdisciplinar na Era planetária, esboçando seus fundamentos epistemológicos e sua posição no campo da ecopedagogia. Salientei os desafios epistemológicos, éticos e políticos que precisamos enfrentar para podermos fazer frente aos impactos destrutivos gerados pela globalização neoliberal apoiada na "tecnociência", reconhecendo nosso Planeta como nossa "Terra-Pátria".

Somos seres inquietos, em busca constante por novidades e pelo controle das coisas que nos cercam. Neste sentido, o pensamento complexo permite que vejamos a crise psicossocioecológica global de uma perspectiva anti-reducionista, como uma teia de interdependências dinâmicas. Ele nos ajuda assim a entender melhor o mundo contemporâneo, a partir de um olhar crítico e de corte transdisciplinar.

No início do Terceiro Milênio, não obstante alguns avanços conquistados nos espaços de gestão governamental e em alguns setores de reorganização da vida coletiva, permanece a impressão de que estamos ainda muito aquém do que seria necessário face ao agravamento da crise global. Seja como for, os pequenos movimentos que vêm sendo acionados em praticamente todas as partes do globo (mesmo ainda que embrionários), servem como modelos e exemplos de ações na contramão da visão mecanicista/capitalista predominante.

Vale a pena ressaltar também as incertezas constitutivas da dinâmica de sistemas socioecológicos hipercomplexos num horizonte de longo prazo. Já se tornou um lugar comum na comunidade de pesquisadores do Sistema-Terra que os resultados de nossas interações não podem ser previstos com a segurança que desejaríamos (apoiados no senso comum). Precisamos, portanto, exercitar uma vigilância sustentada no tempo, vivendo e agindo conforme esse rico cruzamento de interações (não só humanas) nos levem. E não parece descabida a ideia de que, face aos impasses 
do momento, apenas a visualização de um cenário de desastres em série - e irreversíveis - no hábitat planetário poderá gerar a metamorfose cognitiva e ético-política que necessitamos.

Parece ser unanime entre as experiências já realizadas que os saberes constitutivos da ecoformação transdisciplinar precisam ir além do nível de compreensão meramente intelectual. Apesar das diferenças conceituais e metodológicas encontradas nesses autores ${ }^{\text {xiii }}$, todos reconhecem que a crise psicossocioecológica global somente será superada por meio de transformações radicais de visão-de-mundo e de ação-no-mundo, mobilizando instâncias mais profundas do nosso ser - aquilo que conecta com as esferas planetária e cósmica. O nosso "ensino educativo", como diria Morin ao longo de suas reflexões, precisa tocar nosso lado Sapiens, mas também, nosso lado Demens, Ludens e Mythologicus.

A hipótese de trabalho que permeia transversalmente este artigo é a de que o enfoque de ecoformação transdisciplinar poderá contribuir decisivamente - de forma dialógica e complementar - na busca de religação dos conhecimentos técnicos e científicos e dos saberes que são construídos ao longo das experiências vividas no cotidiano. Em outras palavras, poderá promover uma articulação orgânica entre os polos da pesquisa, da ação transformadora e da formação integral de/entre educadores e estudantes. A metamorfose assim gerada poderia ser vista como uma condição sine qua non de êxito na busca de novas formas de vida no hábitat terrestre.

\section{Referências}

AMORIM, Filipi V. Homo Sapiens Sapiens x Homo Sapiens Demens: a educação ambiental em busca das antinomias do Homo Sapiens Degradandis. Reunião Nacional da ANPED, 37. 2015. Florianópolis: UFSC, 2015. Disponível em: <http://www.anped.org.br/sites/default/files/trabalho -gt22-4187.pdf>

BATESON, Gregory. Steps to an ecology of mind. San Francisco: Chandler, 1987.

BESSON-GIRARD, Jean-Claude. Por uma conversão antropológica: o decrescimento é a saída do labirinto. In: LÉNA, Philippe; NASCIMENTO, Elimar P. Enfrentando os limites do crescimento: sustentabilidade, decrescimento e prosperidade. Rio de Janeiro: Garamond, 2012. p. 371-380.

BERTALANFFY, Ludwig von. Teoria geral dos sistemas. Petrópolis: Vozes, 1975.

BOFF, Leonardo. Felicidade interna bruta. 2007. Disponível em: <http://www.dhnet.org.br/direitos/indicadores/felicid ade/boff felicidade interna bruta.pdf $>$

BONNEUIL, Christophe; FRESSOZ, Jean B. L'événement Anthopocène: La Terre, l'histoire et nous. Paris: Seuil, 2016.

CAPRA, Fritjof. O ponto de mutação. Direção: Bernt Amadeus Capra. 1990. (112m).

CARSON, Rachel. Primavera silenciosa. 2. ed. São Paulo: Portico, 1969.

CONNELL, Raewyn. A iminente revolução na teoria social. Revista Brasileira de Ciências Sociais, v. 27, n. 80, p. 9-20, out. 2012.

COTTEREAU, Dominique. Formation entre terre et mer: Alternance écoformative. Paris: L’Harmattan, 2001.

DIAMOND, Jared. Colapso: como as sociedades escolhem o fracasso ou o sucesso. Rio de Janeiro: Record, 2005.

FOUCAULT, Michel. Nascimento da biopolítica: curso dado ao Collège de France (1978-1979). São Paulo: Martins Fontes, 2008.

FREIRE, Paulo. Pedagogia do oprimido. 17. ed. Rio de Janeiro: Paz e Terra, 1987.

FRENK, Gerardo Alatorre; MERÇON, Juliana; GARCÍA, Julieta Alejandra Rosell; REYES, Isabel Bueno García; AYALA-OROZCO, Bárbara; CURIEL, Viridiana Anaid Lobato. Para construer lo común entre los diferentes: Guía para la colaboracíon intersectorial hacia la sustentabilidad. $2016 . \quad$ Disponível em: <https://docs.wixstatic.com/ugd/98d29f_85845f2894 0c4c8a8a2df3249dac7a38.pdf $>$

GALVANI, Pascal; PINEAU, Gaston. Experiências de vida e formação docente: religando saberes um método reflexivo e dialógico. In: MORAES, Maria Cândida de; ALMEIDA, Maria da Conceição de. Os sete saberes necessários à educação do presente: por uma educação transformadora. Rio de Janeiro: Wak Editora, 2012. p. 205-225.

HICKS, David. Lessons for the Future: the missing dimension in education. London: RoutledgeFalmer, 2002. Futures and Education Series.

LORIUS, Claude; CARPENTIER, Laurent. Voyage dans l'Anthropocène. Arles: Actes Sud, 2010. 
MAUSS, Marcel. Sociologia e Antropologia. 2. ed. São Paulo: Cosac Naify, 2007.

MEADOWS, Donella H. MEADOWS, Dennis L. RANDERS, Jorgen. Beyond the Limits: Confronting Global Collapse, Envisioning a Sustainable Future. White River Junction, Vermont: Chelsea Green Publishing, 1993.

MEADOWS, Donella H. Limites do crescimento: um relatório para o Projeto do Clube de Roma sobre o dilema da humanidade. São Paulo: Perspectiva, 1973.

MEADOWS, Donella H. 2004. Limits to Growth: the 30-year update. Chelsea Green Publishing, 2014.

MERÇON, Juliana. Conferência Merçon 2019: Colaboração transdisciplinar e aprendizagem social com e para experiências do Sul Global. Florianópolis, 2019.

MERÇON, Juliana. AYALA-OROZCO, Bárbara. ROSELL, Julieta A. Experiencias de colaboración transdisciplinaria para la sustentabilidad: Construyendo lo Común. Ciudad de México: CopItarXives y Red Temática de Socioecosistemas y Sustentabilidad, Conacyt. 2018. Disponível em: $<$ http://scifunam.fisica.unam.mx/mir/copit/SC0007E S/SC0007ES.pdf $>$

MONEYRON, Anne. Transhumance etéco-savoir: Renaissance des alternatives écoformatives. Paris: L'Harmattan, 2003.

MORIN, Edgar. A cabeça bem-feita: repensar a reforma, reformar o pensamento. 17. ed. Rio de Janeiro: Bertrand Brasil, 2010.

MORIN, Edgar. Os sete saberes à educação do futuro. São Paulo: Cortez; Brasília, DF: Unesco, 2000.

MORIN, Edgar. Para além da globalização e do desenvolvimento: sociedade mundo ou império mundo? In: CARVALHO, Edgard de Assis; MENDONÇA, Terezinha. Ensaios de complexidade 2. Porto Alegre: Sulina, 2003. p. 720.

MORIN, Edgar; KERN, Anne B. Terra-Pátria. Porto Alegre: Sulina, 1995.

NICOLESCU. Basarab. O manifesto da transdisciplinaridade. São Paulo: Triom, 2005.

NÚCLEO TRANSDISCIPLINAR DE MEIO AMBIENTE E DESENVOLVIMENTO (NMD). Apresentação. 2019. Disponível em: <http://nmd.ufsc.br/>

O'SULLIVAN, Edmund V. "The Project and Vision of Transformative Learning". In: O'SULLIVAN, E., MORRELL, A.; O'CONNOR, M. Expanding the
Boundaries of Transformative Learning: essays on theory and praxis. New York: Palgrave Macmillan, 2002, p.1-12.

ORGANIZAÇÃO DAS NAÇÕES UNIDAS (ONU). Declaração da Conferência de ONU no Ambiente Humano. 1972. Disponível em: <www.mma.gov.br/estruturas/agenda21/arquivos/e stocolmo.doc $>$

PIAGET, Jean. A epistemologia genética. São Paulo: Abril Cultural, 1978.

PINEAU, Gaston Pour une écoformation. Former à et par l'environnement. Éducation Permanente, n. 148, 2001.

PINEAU, Gaston; GALVANI, Pascal. Experiências de vida e formação docente: religando saberes - um problema paradigmático mais do que programático. In: MORAES, Maria Cândida de; ALMEIDA, Maria da Conceição de. Os sete saberes necessários à educação do presente: por uma educação transformadora. Rio de Janeiro: Wak Editora, 2012. p. 185-204.

REDSOCIOECOS. Início. 2019. Disponível em: <https://www.redsocioecos.org/>

RIST, Gilbert. O decrescimento para todos? In: LÉNA, Philippe; NASCIMENTO, Elimar Pinheiro do Enfrentando os limites do crescimento: sustentabilidade, decrescimento e prosperidade. Rio de Janeiro: Garamond, 2012, p. 135-146.

ROGERS, Martha. Learning about Global Futures: an exploration of learning processes and changes in adults. Tese (Doutorado) - University of Toronto, Toronto, 1994.

RUSSEL, Peter. 1992. O buraco branco no tempo. Direção: Chris Hall. Fotografia: Joe Sohm e Mark Adwards. 1992. (27m).

STERLING, Stephen R. Transformative learning and sustainability: sketching the conceptual ground. Learning and teaching in Higher Education, n. 5, p. 17-33, 2010. Disponível em: $<$ http://dl.icdst.org/pdfs/files/0cd7b8bdb08951af53e 5927e86938977.pdf>

THIOLLENT, Michel J. M. COLETTE, Maria M. Pesquisa-ação, formação de professores e diversidade. Acta Scientiarum. Human and Social Sciences, Maringá, v. 36, n. 2, p. 207-216, jul./dec., 2014.

TURNER, Graham M. A comparison of the limits to growth with thirty years of reality. CSIRO Working Paper Series, 2008.

VIEIRA, Paulo F. Ecodesenvolvimento: desvelando novas formas de resistência no antropoceno. In: GOMES, Anderson M.; SOUZA, Cristiane M. M.; 
BRAUN, Samara; TABOSA, Ana Paula. Novos talentos FURB: processo de educação para o ecodesenvolvimento. Blumenau: Nova Letra, 2016, p. 23-64

VIEIRA, Paulo F.; BERKES, Fikret; SEIXAS, Cristina S. Gestão integrada e participativa de recursos naturais: conceitos, métodos e experiências. Florianópolis: APED e SECCO, 2005.

VIEIRA, Paulo F. Impactos da pesquisa biológica na ciência política contemporânea. Ciências Sociais Hoje, p. 192-207, 1991.

${ }^{\mathrm{i}}$ Morin (2010) em seu paradigma sistêmico-complexo, propõe a relação equivalente entre todo-parte, além do princípio recursivo dos sistemas vivos que é baseado na auto-organização. Esta compreensão é gênese do entendimento de que nossa existência partiu do nascimento de nosso Universo, que gerou nosso planeta e as condições que permitem nossa existência. Para Morin (2010; MORIN; KERN, 1995) vivemos uma aventura cósmica pois não podemos controlar ou mesmo prever todos os acontecimentos que permeiam nossa existência e que viver com a incerteza é algo fundamental do qual compartilhamos. Ao fazermos ciência sem considerarmos suas consequências (mesmo que estas sejam imprevisíveis) e apenas focada nos interesses econômicos ou desenvolvimentistas, é continuarmos guiando-nos pelo caminho que, ao que os indicadores apontam desde a década de 1960, levar-nos-á a uma extinção prematura.

ii Considerados conceitos polêmicos, pois, enquanto alguns autores os consideram como mais uma possível alavanca aos ideários neoliberais, outros os veem enquanto "saída do labirinto" da crise psicossocioecológica global (RIST, 2012; BESSONGIRARD, 2012)

iiic، $\mathrm{O}$ autor defende que o Homo sapiens sapiens, o humano em sua nomenclatura científica moderna, não é, unicamente, sapiência, sabedoria e razão. Ao considerar o lado demens, ludens e mythologicus do humano, Morin insere-se na contramão do tradicionalismo cientificista que simplifica/reduz e objetifica o que pretende explorar e conhecer. Ademais, para o pensador francês, a nossa humanidade comporta, igualmente, nossa desumanidade" (AMORIM, 2015: p. 04-05). A ação humana não ocorre isolada, ela é parte de um turbilhão de interações e retroações. Neste contexto, as ideias ganham vida própria; precisando ser [meta]refletidas eticamente no tempo e no espaço.

${ }^{\text {iv }}$ Alguns dos autores citados utilizam o conceito de "policrise global" em seus trabalhos (MORIN; KERN, 1995; PINEAU; GALVANI, 2012). Apesar disso, optei pelo uso do conceito de "crise psicossocioecológica global" por compreender que este é um conceito atualizado e que tem como intuito de situar tanto a existência da crise quanto de superar possíveis dualismos (BONNEUIL; FRESSOZ, 2016; LORIUS; CARPENTIER, 2010).
VIGOTSKII, Lev S.; ROMANOVICH, Luria; LEONTIEV, Alex N. Linguagem, desenvolvimento e aprendizagem. 11. ed. São Paulo: ícone, 2010. Coleção Educação Crítica.

WEDY, Gabriel. Desenvolvimento sustentável na era das mudanças climáticas: um direito fundamental. São Paulo: Saraiva, 2018.
${ }^{\mathrm{v}}$ O biólogo alemão Ludwig von Bertalanffy (1975) foi um dos principais autores no desenvolvimento de uma teoria geral dos sistemas, que se ocupa das semelhanças, sem prejuízo às diferenças. Entendido enquanto um modelo aberto, complexo e de interação contínua, que serviu de base às elucubrações de Morin.

vi Além disso, Graham Turner (2008) apresentou uma comparação sobre o relatório e os acontecimentos das últimas três décadas e que evidenciam suas previsões quanto aos colapsos sociais e econômicos para o século XXI.

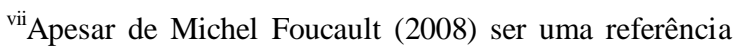
nas ciências sociais e humanas no que concerne a categoria de biopolítica, utilizando-a enquanto crítica às formas de domínio da vida pela expansão liberal, o conceito é utilizado pelos autores citados neste texto enquanto possibilidade de avanços no conhecimento a respeito de nossa condição terrestre mas, sem deixar de reconhecer os interesses pelos jogos de poder do qual Foucault se ocupa.

viii O conceito da "dádiva" foi estudado pelo sociólogo francês Marcel Mauss (2007) e neste artigo é utilizado a partir do chamado Movimento Anti-utilitarista nas Ciências Sociais - MAUSS. Movimento criado na década de 1980. O conceito é compreendido enquanto um padrão de inter-relação entre os seres humanos, um movimento cíclico onde se dá e se recebe mutuamente e que alimentaria alianças recorrentes em comunidades locais. A categoria em si representa o contraponto ao interesse material egoísta.

${ }^{\text {ix }}$ Há duas formas de pensar o "Sul": uma como hemisférios, oriunda da geografia, e outra, que nos interessa aqui, como Sul global, oriundo da geopolítica do conhecimento, compreendido como periférico aos grandes centros de conhecimento (CONNELL, 2012; MERÇON; AYALA-OROZCO; ROSELL, 2018; RIST, 2012).

${ }^{x}$ Que na concepção do autor é mais completo do que somente as visões separadas de educação e de ensino. Para Morin (2010) o "ensino educativo" transmite cultura.

${ }^{\mathrm{x}}$ Talvez um dos principais exemplos dessa visão seja encontrado no Butão e a medição de sua FIB (Felicidade Interna Bruta) como contraponto ao PIB (Produção Interna Bruta). Neste sistema, o objetivo é o de 
desenvolver e medir indicadores que contemplem os FIB nas distintas dimensões sociais, aliando desenvolvimento econômico, cultural, espiritual, educacional entre outros (BOFF, 2007).

xii Baseando-se na extensa e detalhada obra de Gregory Bateson (1987), Sterling (2010), apresenta as três ordens em que se apresenta a aprendizagem e a mudança. A mudança de primeira ordem está relacionada com a "aprendizagem básica", sem mudança de valores. Já na mudança de segunda ordem açambarca alteração de valores, mas não chega ao mesmo nível de reflexão crítica sobre o próprio pensamento como ocorre nas mudanças de terceira ordem.

xiii Termos como "complexidade", "Sistemismo" e "transdisciplinaridade" ou ainda "ecoformação transdisciplinar", "aprendizagem transformativa" e "ecopedagogia transdisciplinar" possuem bases conceituais distintas, apesar disso, não são completamente contraditórias, mas sim, são complementares. 